\title{
New Insights into the Microbial Degradation of $D$-Cyphenothrin in Contaminated Water/Soil Environments
}

\author{
Yaohua Huang ${ }^{1,2} \oplus$, Ziqiu Lin ${ }^{1,2}$, Wenping Zhang ${ }^{1,2}$, Shimei Pang ${ }^{1,2}$, Pankaj Bhatt ${ }^{1,2}$, \\ Eldon R. Rene ${ }^{3}$, Alagarasan Jagadeesh Kumar ${ }^{4}$ and Shaohua Chen $1,2, *$ (D) \\ 1 State Key Laboratory for Conservation and Utilization of Subtropical Agro-bioresources, Guangdong \\ Province Key Laboratory of Microbial Signals and Disease Control, Integrative Microbiology Research \\ Centre, South China Agricultural University, Guangzhou 510642, China; 20183138021@stu.scau.edu.cn (Y.H.); \\ 20192047010@stu.scau.edu.cn (Z.L.); 20191047008@stu.scau.edu.cn (W.Z.); \\ 20192047012@stu.scau.edu.cn (S.P.); pankajbhatt.bhatt472@gmail.com (P.B.) \\ 2 Guangdong Laboratory for Lingnan Modern Agriculture, Guangzhou 510642, China \\ 3 Department of Environmental Engineering and Water Technology, IHE Delft Institute for Water Education, \\ 2601DA Delft, The Netherlands; e.raj@un-ihe.org \\ 4 School of Chemistry and Chemical Engineering, Jiangsu University, Zhenjiang 212013, China; \\ jaga.jagadeesh1987@gmail.com \\ * Correspondence: shchen@scau.edu.cn; Tel.: +86-20-8528-8229; Fax: +86-20-8528-0292
}

Received: 24 February 2020; Accepted: 20 March 2020; Published: 26 March 2020

\begin{abstract}
Persistent use of the insecticide D-cyphenothrin has resulted in heavy environmental contamination and public concern. However, microbial degradation of D-cyphenothrin has never been investigated and the mechanism remains unknown. During this study, for the first time, an efficient D-cyphenothrin-degrading bacterial strain Staphylococcus succinus HLJ-10 was identified. Response surface methodology was successfully employed by using Box-Behnken design to optimize the culture conditions. At optimized conditions, over $90 \%$ degradation of D-cyphenothrin (50 $\mathrm{mg} \cdot \mathrm{L}^{-1}$ ) was achieved in a mineral salt medium within $7 \mathrm{~d}$. Kinetics analysis revealed that its half-life was reduced by $61.2 \mathrm{~d}$, in comparison with the uninoculated control. Eight intermediate metabolites were detected in the biodegradation pathway of D-cyphenothrin including cis-D-cyphenothrin, trans-D-cyphenothrin, 3-phenoxybenzaldehyde, $\alpha$-hydroxy-3-phenoxy-benzeneacetonitrile, trans-2,2-dimethyl-3-propenyl-cyclopropanol, 2,2-dimethyl-3-propenyl-cyclopropionic acid, trans-2,2-dimethyl-3-propenyl-cyclopropionaldehyde, and 1,2-benzenedicarboxylic acid, dipropyl ester. This is the first report about the degradation of D-cyphenothrin through cleavage of carboxylester linkage and diaryl bond. In addition to degradation of D-cyphenothrin, strain HLJ-10 effectively degraded a wide range of synthetic pyrethroids including permethrin, tetramethrin, bifenthrin, allethrin, and chlorempenthrin, which are also widely used insecticides with environmental contamination problems. Bioaugmentation of D-cyphenothrin-contaminated soils with strain HLJ-10 substantially enhanced its degradation and over $72 \%$ of D-cyphenothrin was removed from soils within $40 \mathrm{~d}$. These findings unveil the biochemical basis of a highly efficient D-cyphenothrin-degrading bacterial isolate and provide potent agents for eliminating environmental residues of pyrethroids.
\end{abstract}

Keywords: D-cyphenothrin; degradation pathway; kinetics; Staphylococcus succinus; bioaugmentation

\section{Introduction}

D-cyphenothrin [cyano-(3-phenoxyphenyl) methyl 2,2-dimethyl-3-(2-methyl-1-propenyl) cyclopropanecarboxylate] is one of the most popular synthetic pyrethroids (SPs), used for the control 
a broad-spectrum of insect pests [1]. Lower toxicity and higher insecticidal potential has made D-cyphenothrin highly suitable for indoor control of sanitary pests (cockroaches, mosquitoes, houseflies, fleas, and mites) [2-5]. However, persistent use of D-cyphenothrin affects non-target organisms and contaminates terrestrial and aquatic environments [6]. Agricultural countries produce large amounts of agro-wastewater that is directly discharged into natural channels, posing serious environmental effects [7]. In the aqueous phase, D-cyphenothrin is separated from water due to non-polar property and adsorbs in sediments [8]. Indigenous microorganisms metabolize these pyrethroids through the hydrolysis of ester bond and oxidation of microsomal cytochrome P450s $[9,10]$. Despite this, some studies have reported that the concentration of D-cyphenothrin detected frequently was higher than the acceptable daily intake (ADI) [11].

Humans spend most of their lives indoors and are exposed to various indoor pollutants including D-cyphenothrin [12,13]. Long-term exposure to pyrethroids can affect human health. Stiller-Winkler et al. have demonstrated decreased concentrations of humoral and cellular immune function parameters with the increased exposure of pesticide applicators to SPs [14]. Previous studies have indicated that prolonged D-cyphenothrin exposure may cause toxicity to the human reproductive system [15]. A survey conducted by Le Grand et al. detected pyrethroid metabolite 3-phenoxybenzoic acid (3-PBA) in the urine samples of all 39 French volunteers who were not exposed to SPs [16]. The concentration of metabolites was noted to be higher in the urine than blood [17]. These results reveal potential hazards of SPs, including D-cyphenothrin, to human health and ecosystems.

The persistent use of D-cyphenothrin and its environmental residues has raised serious concerns. Therefore, there is an urgent need to develop effective strategies to solve D-cyphenothrin related problems. Bioremediation is a cost-effective, eco-friendly, and highly efficient approach to eliminate organic contaminants and pyrethroid residues [18-20]. In recent years, several pyrethroid-degrading bacteria have been reported to utilize SPs as a sole carbon source for their growth. These bacteria include Pseudomonas fulva P31, Streptomyces aureus HP-S-01, Bacillus subtilis BSF01, and Rhodopseudomonas sp. PSB07-6 [21-27]. Researchers have also studied pyrethroid-degrading fungi such as Aspergillus sp. CBMAI 1829, Penicillium raistrickii CBMAI 931, and Cladosporium sp. HU [28-30]. Microorganisms-based SPs degradation causes ester cleavage to form 3-PBA which is further metabolized [31]. Carboxylesterases-based hydrolysis of SPs and other ester-containing compounds has already been documented [32,33].

To date, microbial degradation of D-cyphenothrin has never been investigated. In this study, D-cyphenothrin biodegradation experiments were performed with the following objectives: (I) to isolate and characterize the D-cyphenothrin-degrading strain from activated sludge, (II) to optimize D-cyphenothrin biodegradation conditions using response surface methodology, (III) to estimate the degradation kinetics of D-cyphenothrin and other SPs, (IV) to identify the intermediate metabolites formed during D-cyphenothrin degradation, and (V) to investigate the bioremediation of D-cyphenothrin in sterilized and unsterilized soil environments.

\section{Materials and Methods}

\subsection{Chemicals and Medium}

D-cyphenothrin (98\% purity) was obtained from Wuhan Yuancheng Pharm Co., Ltd., China. Technical-grade tetramethrin (99\%), permethrin $(97 \%)$, bifenthrin $(96 \%)$, allethrin $(93 \%)$, and chlorempenthrin (94\%) were purchased from Sigma-Aldrich, USA. Chromatographic grade acetone and acetonitrile was obtained from Fisher Scientific, USA. All other chemicals and solvents used in this study were of analytical grade. Stock solutions were prepared by dissolving SPs in chromatographic grade acetone at a concentration of $10 \mathrm{~g} \cdot \mathrm{L}^{-1}$ and stored in dark bottles at $4{ }^{\circ} \mathrm{C}$.

Luria-Bertani medium (LB) was composed of $10 \mathrm{~g}$ tryptone; $5 \mathrm{~g}$ yeast extract; and $10 \mathrm{~g} \mathrm{NaCl}$ dissolved in 1-L distilled water. Mineral salt medium (MSM) $\left(\mathrm{g} \cdot \mathrm{L}^{-1}\right)$ containing $\left(\mathrm{NH}_{4}\right)_{2} \mathrm{SO}_{4}$, 2; $\mathrm{Na}_{2} \mathrm{HPO}_{4} \cdot 12 \mathrm{H}_{2} \mathrm{O}, 1.5 ; \mathrm{KH}_{2} \mathrm{PO}_{4}, 1.5 ; \mathrm{MgSO}_{4} \cdot 7 \mathrm{H}_{2} \mathrm{O}, 0.2 ; \mathrm{CaCl}_{2} \cdot 2 \mathrm{H}_{2} \mathrm{O}, 0.01$; and $\mathrm{FeSO}_{4} \cdot 7 \mathrm{H}_{2} \mathrm{O}, 0.001$ was 
used for biodegradation assays whereas solid medium was additionally added with 1.5\% agar. The $\mathrm{pH}$ of both culture media was adjusted to 7.0 and autoclaved at $121^{\circ} \mathrm{C}$ for $20 \mathrm{~min}$.

\subsection{Isolation and Identification of D-Cyphenothrin-Degrading Bacterial Isolates}

Pesticide activated sludge was collected from a farmland in Harbin, Heilongjiang Province, China. Five $\mathrm{g}$ of soil sample was added to a $250 \mathrm{~mL}$ Erlenmeyer flask containing $50 \mathrm{~mL}$ of sterilized MSM medium. Bacterial culture was enriched by adding D-cyphenothrin stock in the flask to make a final concentration of $50 \mathrm{mg} \cdot \mathrm{L}^{-1}$. Flask was incubated at $30^{\circ} \mathrm{C}$ and $200 \mathrm{rpm}$ in a rotary shaker. After $7 \mathrm{~d}, 5 \mathrm{~mL}$ culture was transferred into a new flask containing $50 \mathrm{~mL}$ fresh MSM medium at a concentration of $100 \mathrm{mg} \cdot \mathrm{L}^{-1}$. The same method was continuously repeated to prepare enrichment culture concentrations of 200,400 , and $800 \mathrm{mg} \cdot \mathrm{L}^{-1}$, respectively. Final enrichment culture $\left(800 \mathrm{mg} \cdot \mathrm{L}^{-1}\right)$ was serially diluted and spread on MSM plates (1.5\% agar) containing D-cyphenothrin $\left(50 \mathrm{mg} \cdot \mathrm{L}^{-1}\right)$. Plates were incubated at $30{ }^{\circ} \mathrm{C}$ for $3 \mathrm{~d}$ to isolate individual colonies. Individual colonies were selected and purified by re-streaking three times, and preserved with $15 \%$ glycerol at $-80{ }^{\circ} \mathrm{C}$. D-cyphenothrin degradation potential of the isolate was determined by high-performance liquid chromatography (HPLC) (Waters, Milford, MA, USA).

Bacterial strain HLJ-10 was identified and characterized by morphology, physio-biochemical characteristics, and genetic analysis of $16 \mathrm{~S}$ rDNA gene sequence. After two days of incubation at $30^{\circ} \mathrm{C}$ and $200 \mathrm{rpm}$, morphological characteristic of strain HLJ-10 (size, color, surface, edge, and texture) were studied under light microscope (Olympus, Tokyo, Japan) and scanning electron microscope (XL-30 ESEM, Philips Optoelectronics Co., Ltd., Holland) [34]. Physio-biochemical assays were conducted with reference to previous literature [35]. The 16S rRNA gene was PCR-amplified with universal set of primer pairs (forward primer: 5'-TGACGAGTGGCGGACGGGTG-3' and reverse primer: 5'-CCATGGTGTGACGGGCGGTGTG-3') purchased from Genewiz, NJ, USA. The resulting sequence of PCR product (1136 bp) was compared in Basic Local Alignment Search Tool (BLAST) of National Center for Biotechnology Information (NCBI). Multiple alignment of 16S rRNA were performed in DNAMAN (version 6.0, LynnonBiosoft, San Ramon, CA, USA) and phylogenetic tree was constructed in MEGA 7.0 (Pennsylvania State University, University Park, PA, USA) by following the neighbor-joining method according to Tamura et al. [36].

\subsection{Optimization of Conditions for D-Cyphenothrin Degradation}

Stored culture $\left(-80^{\circ} \mathrm{C}\right)$ of strain HLJ-10 was thawed and activated by streaking on LB agar plates. Two days later, single colonies were inoculated into LB liquid medium for $24 \mathrm{~h}$. After adjusting the OD (optical density) to $0.8,1 \mathrm{~mL}$ of bacterial broth was taken in a $2 \mathrm{~mL}$ centrifuge tube and centrifuged $(4000 \times g, 4 \mathrm{~min})$ to collect the cells. The cells were washed twice with sterile normal saline and re-suspended. Re-suspended broth was transferred to $50 \mathrm{~mL}$ MSM medium containing D-cyphenothrin $\left(50 \mathrm{mg} \cdot \mathrm{L}^{-1}\right)$ and incubated in the dark at $30^{\circ} \mathrm{C}$ and $200 \mathrm{rpm}$. The experiment was set up in triplicate and uninoculated flasks served as controls. The growth OD of strain HLJ-10 was monitored with UV/visible spectrophotometer (Shimadzu UV-2410, Shimadzu, Japan) at $600 \mathrm{~nm}$ and residual amount of D-cyphenothrin was determined by HPLC.

Response surface methodology (RSM) designed by Box-Behnken was used to optimize the crucial factors and interactive influences of strain HLJ-10 degradation activity. According to the preliminary one-factor-at-a-time experiment results, three main factors (temperature, $\mathrm{pH}$, and inoculum size) were selected as independent variables to achieve optimal conditions for D-cyphenothrin degradation. Range and center values of the three independent variables are shown in Table 1. Degradation of $50 \mathrm{mg} \cdot \mathrm{L}^{-1} \mathrm{D}$-cyphenothrin in MSM after $7 \mathrm{~d}$ was considered as the dependent variable. Box-Behnken design with three-variables consisting of 17 experimental runs in triplicate at the midpoint was generated by Design Expert version 12.0 (Stat-Ease, MN, USA). Randomized block design was followed 
and experimental data were subjected to regression analysis. The data were analyzed by response surface regression program and fitted to the following quadratic polynomial equation:

$$
Y_{i}=b_{0}+\sum b_{i} X_{i}+\sum b_{i j} X_{i} X_{j}+\sum b_{i i} X_{i}^{2}
$$

where $Y_{i}$ is the predicted response, $X_{i}$ and $X_{j}$ are variables, $b_{0}$ is the constant, $b_{i}$ is the linear coefficient, $b_{i j}$ is the interaction coefficient, and $b_{i i}$ is the quadratic coefficient.

Table 1. The code and levels of three independent variables used in the central composite rotatable design.

\begin{tabular}{ccccc}
\hline \multirow{2}{*}{ Independent Variables } & Code & \multicolumn{3}{c}{ Code Levels of Variables } \\
\cline { 3 - 5 } & & $\mathbf{- 1}$ & $\mathbf{0}$ & $\mathbf{1}$ \\
\hline Temperature $\left({ }^{\circ} \mathrm{C}\right)$ & $X_{1}$ & 25 & 30 & 35 \\
$\mathrm{pH}$ & $X_{2}$ & 5 & 7 & 9 \\
Inoculum size (OD) & $X_{3}$ & 0.3 & 0.8 & 1.3 \\
\hline
\end{tabular}

To confirm the effect of strain HLJ-10 on D-cyphenothrin degradation, a first-order kinetic model was followed to describe the biodegradation process:

$$
\mathrm{C}_{\mathrm{t}}=\mathrm{C}_{0} \times \mathrm{e}^{-\mathrm{kt}}
$$

where $C_{0}$ is the initial concentration of D-cyphenothrin $\left(\mathrm{mg} \cdot \mathrm{L}^{-1}\right), C_{\mathrm{t}}$ is the content of D-cyphenothrin at time $t, k$ is the degradation constant $\left(\right.$ day $\left.^{-1}\right)$, and $t$ is the degradation time (days).

Equation (3) was used to calculate the theoretical half-life $\left(t_{1 / 2}\right)$ of D-cyphenothrin: $t_{1 / 2}=\frac{\ln (2)}{k}$

$$
t_{1 / 2}=\ln 2 / k
$$

where $\ln (2)$ is the natural logarithm of 2 and $k$ is the degradation constant.

\subsection{Substrate Range of Strain HLJ-10 and Concentration Range of D-Cyphenothrin}

The degradation potential of strain HLJ-10 was studied against various SPs (permethrin, bifenthrin, tetramethrin, allethrin, and chlorempenthrin) and different concentrations of D-cyphenothrin. Various SPs were added to the $50 \mathrm{~mL}$ of MSM medium at a final concentration of $50 \mathrm{mg} \cdot \mathrm{L}^{-1}$, respectively. D-cyphenothrin was added to the $50 \mathrm{~mL}$ MSM medium to make a final concentration of 25, 50, 100, 200, 400 , and $800 \mathrm{mg} \cdot \mathrm{L}^{-1}$, respectively. The experiments were performed in triplicate with uninoculated flasks as controls. After $7 \mathrm{~d}$ of shaking in dark at $30^{\circ} \mathrm{C}$ and $200 \mathrm{rpm}$, the samples were extracted and analyzed by HPLC.

\subsection{Identification of Intermediate Metabolites of D-Cyphenothrin}

To study the metabolic pathway of strain HLJ-10 during D-cyphenothrin degradation, samples were collected from MSM on day 1,3,5, and 7, respectively. Metabolites were detected by gas chromatography-mass spectrometry (GC/MS) (Agilent 6890N/5975, Santa Clara, CA, USA) and results were matched with standard compounds in the National Institute of Standards and Technology (NIST) library database.

\subsection{Biodegradation of D-Cyphenothrin in Soils}

To analyze the effect of strain HLJ-10 in soil, an experiment with sterile and nonsterile soil was planned. Soil samples for this experiment were collected from the top 5-20 cm layer of a field located in South China Agricultural University, Guangdong Province, China where D-cyphenothrin had never been applied. Physicochemical parameters for the soil were characterized as $(\mathrm{g} / \mathrm{kg}$ of dry weight): 
organic matter, 10.5; total N, 0.5; total P, 0.4; total K, 18.2; and pH, 6.9. Soil consisted of sand, 65.0\%; silt, $28.0 \%$; and clay, $7.0 \%$. Soil samples were naturally air dried indoors and sieved (2 mm) for bioremediation studies [18].

Soil was autoclaved at $121^{\circ} \mathrm{C}$ for $1 \mathrm{~h}$ to completely remove indigenous microbial communities. Then, $250 \mathrm{~g}$ sterile and nonsterile soil samples were placed in a $500 \mathrm{~mL}$ Erlenmeyer flask, respectively. D-cyphenothrin solution was added to a final concentration of $50 \mathrm{mg} \cdot \mathrm{kg}^{-1}$ in each flask. Soil moisture content was adjusted to $40 \%-50 \%$ with sterile deionized water. Approximately $6.0 \times 10^{8} \mathrm{CFU} \cdot \mathrm{mL}^{-1}$ bacterial cell suspension was inoculated to sterile and nonsterile soils, respectively, whereas uninoculated samples served as the control. After complete mixing, soil remediation experiments were carried out in the dark at $30^{\circ} \mathrm{C}$. Then, $10 \mathrm{~g}$ soil samples were collected on 5 th, $10 \mathrm{th}, 15 \mathrm{th}, 25 \mathrm{th}$, and 40th day for extraction.

\subsection{Extraction method of D-Cyphenothrin}

To extract D-cyphenothrin from MSM medium, a $50 \mathrm{~mL}$ centrifuge tube was used instead of the traditional separatory funnel. Then, $10 \mathrm{~mL}$ of the collected sample was added to a $50 \mathrm{~mL}$ centrifuge tube and $10 \mathrm{~mL}$ acetone was added. Tubes were vortexed for $10 \mathrm{~s}$ followed by ultrasonication for $20 \mathrm{~min}$. Then, $15 \mathrm{~mL}$ ethyl acetate was added to the tube and vortexed for $1 \mathrm{~min}$. Tubes were kept at room temperature until the aqueous and organic phases were clearly layered. Upper organic phase was transferred to a new $50 \mathrm{~mL}$ centrifuge tube, $15 \mathrm{~mL}$ ethyl acetate was re-added, and the same procedure was repeated. Organic phases were combined in the new tube and original tubes were discarded. About $10 \mathrm{~g}$ of anhydrous sodium sulfate was added to the tube containing organic phase, vortexed for $30 \mathrm{~s}$, and kept for $20 \mathrm{~min}$. Subsequently, the organic phase was transferred to a $100 \mathrm{~mL}$ flat-bottom flask and dried by vacuum evaporation. D-cyphenothrin residues and metabolites were recovered by chromatographic acetonitrile. Recovered samples were further collected by using $1 \mathrm{~mL}$ injector and $0.22 \mu \mathrm{m}$ filter membrane and stored in brown bottles at $4{ }^{\circ} \mathrm{C}$ before HPLC detection.

\subsection{Analytical Methods}

D-cyphenothrin was quantified with Waters 2690 HPLC system equipped with a Phenomenex $\mathrm{C}_{18}$ reverse phase column $(250 \mathrm{~nm} \times 4.60 \mathrm{~mm}, 5 \mu \mathrm{m})$ and $U V$ detector. Mobile phase was composed of acetonitrile and deionized water $(75: 25)$ at a flow rate of $1.0 \mathrm{~mL} \cdot \mathrm{min}^{-1}$. Injection volume and detection wavelength were $10 \mu \mathrm{L}$ and $253 \mathrm{~nm}$, respectively. Retention times of D-cyphenothrin, permethrin, bifenthrin, tetramethrin, allethrin, and chlorempenthrin remained as 8.97, 14.04, 20.99, 6.78, 7.22, and $10.78 \mathrm{~min}$, respectively.

D-cyphenothrin metabolites were identified in Agilent 6890N/5975 GC/MS system equipped with auto-sampler, an on-column, split/splitless capillary injection system, and HP-5MS capillary column $(30.0 \mathrm{~m} \times 250 \mu \mathrm{m} \times 0.25 \mu \mathrm{m})$ with array detector. Helium was used as carrier gas at a flow rate of $1.5 \mathrm{~mL} \cdot \mathrm{min}^{-1}$. Analytical mode was scanned from 30-500 $\mathrm{nm}$. The column temperature was first held at $90{ }^{\circ} \mathrm{C}$ for $2 \mathrm{~min}$, raised at $6^{\circ} \mathrm{C} \cdot \mathrm{min}^{-1}$ to $150{ }^{\circ} \mathrm{C}$ for $1 \mathrm{~min}, 10^{\circ} \mathrm{C} \cdot \mathrm{min}^{-1}$ to $180{ }^{\circ} \mathrm{C}$ for $4 \mathrm{~min}$, and finally $20^{\circ} \mathrm{C} \cdot \mathrm{min}^{-1}$ to keep at $260^{\circ} \mathrm{C}$ for $10 \mathrm{~min}$. Temperatures corresponding to transfer line and ion source were 280 and $230^{\circ} \mathrm{C}$, respectively. The column outlet was directly inserted into electron ionization source block at $70 \mathrm{eV}$. The injection volume was $1.0 \mu \mathrm{L}$ with splitless sampling at $250{ }^{\circ} \mathrm{C}$ [37].

\section{Results and Discussion}

\subsection{Isolation and Characterization of Strain HLJ-10}

Activated sludge collected from Harbin, Heilongjiang Province, had a large number of isolates with various characteristics. Isolates were obtained in MSM agar plates containing $50 \mathrm{mg} \cdot \mathrm{L}^{-1}$ D-cyphenothrin. One of the isolates utilized D-cyphenothrin as a carbon and energy source to grow and was designated as HLJ-10. Gram staining characterized this isolate as Gram-positive strain. Scanning electron microscope (SEM) revealed that strain HLJ-10 was nearly ball-shaped having a 
diameter of approximately 0.7-1 $\mu \mathrm{m}$. Strain HLJ-10 colonies appeared light yellow, smooth, moist, opaque, and with irregular edges, on LB plates. Detailed appearance and scanning electron micrograph of the strain HLJ-10 are shown in Figure S1. The optimum degradation temperature and $\mathrm{pH}$ were found to be about $32{ }^{\circ} \mathrm{C}$ and 8.0 respectively, and could grow with $\mathrm{NaCl}$ (up to $15 \%$ ) in $\mathrm{LB}$ broth. Strain HLJ-10 exhibited significant degradation potential in the $\mathrm{pH}$ range of 5-11 but failed to grow at pH 3. Physiological and biochemical tests showed positive results in Gram-staining, starch hydrolysis, gelatin liquefaction, and urease tests, whereas negative results were noted in esculin hydrolysis, sorbierite, and raffinose (Table S1). Turbid growth was observed in LB broth medium after $24 \mathrm{~h}$ of incubation in shaker at $30^{\circ} \mathrm{C}$ and $200 \mathrm{rpm}$.

Phylogenetic analysis of $16 \mathrm{~S}$ rDNA gene sequence indicated that strain HLJ-10 belongs to the genus Staphylococcus and shares high similarity with S. succinus subsp. AMG-D1 (GenBank accession number NR028667) (Figure 1). Partial 16S rDNA gene sequence of strain HLJ-10 was submitted to the GenBank under the accession number MN396450. Based on the 16S rRNA analysis and morphology, the strain HLJ-10 was identified as Staphylococcus succinus. S. succinus is a widespread bacterium in various natural habitats and possesses catabolic capabilities. Several potent microbial genera have been reported for SPs biodegradation including Micrococcus, Ochrobactrum, Raoultella, Klebsiella, Brevibacterium, Candida, Bacillus, and Pseudomonas [19,38-41]. However, degradation of xenobiotic compounds by genus Staphylococcus has not received the attention it deserves and this study for the first time presented SPs degradation by S. succinus.
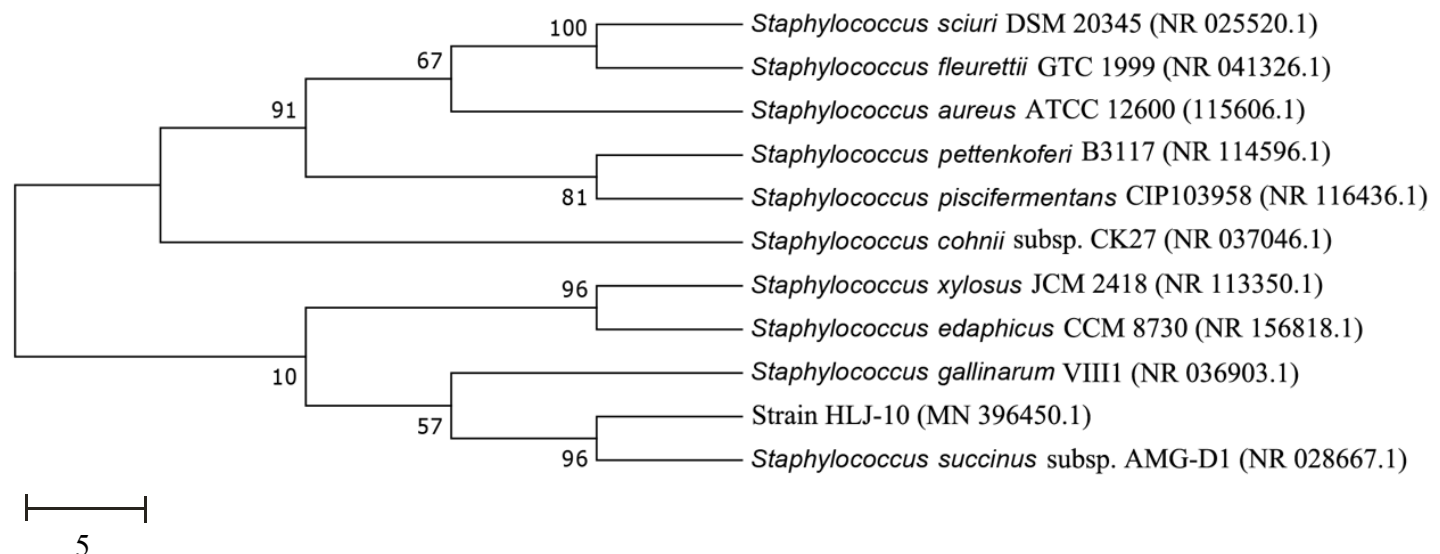

Figure 1. Phylogenetic tree based on $16 \mathrm{~S}$ rDNA sequences of Staphylococcus succinus HLJ-10 and representative Staphylococcus succinus. Numbers in parentheses represent sequence accession number in GenBank. Numbers at nodes indicate bootstrap values. Bar represents sequence divergence.

\subsection{Growth of Isolate and Kinetic Analysis of Degradation Process}

Degradation kinetics of D-cyphenothrin and growth of strain HLJ-10 were simultaneously investigated in MSM medium with $50 \mathrm{mg} \cdot \mathrm{L}^{-1} \mathrm{D}$-cyphenothrin. As shown in Figure 2, there was no lag phase during the growth of strain HLJ-10, indicating that it effectively utilized D-cyphenothrin as a growth substance by degrading $75.8 \%$ in $72 \mathrm{~h}$. D-cyphenothrin degradation was correlated with bacterial cell density and biodegradation of D-cyphenothrin rapidly increased during exponential phase (72 h), whereas it slowed down in stationary phase. Approximately $92.8 \%$ of D-cyphentorhrin was degraded on the 7th day in the dark. HPLC analysis of D-cyphenothrin degradation by strain HLJ-10 over time is shown in Figure S2. At the same time, no significant change in D-cyphenothrin concentration was observed in the control flasks without bacterial inoculum. 


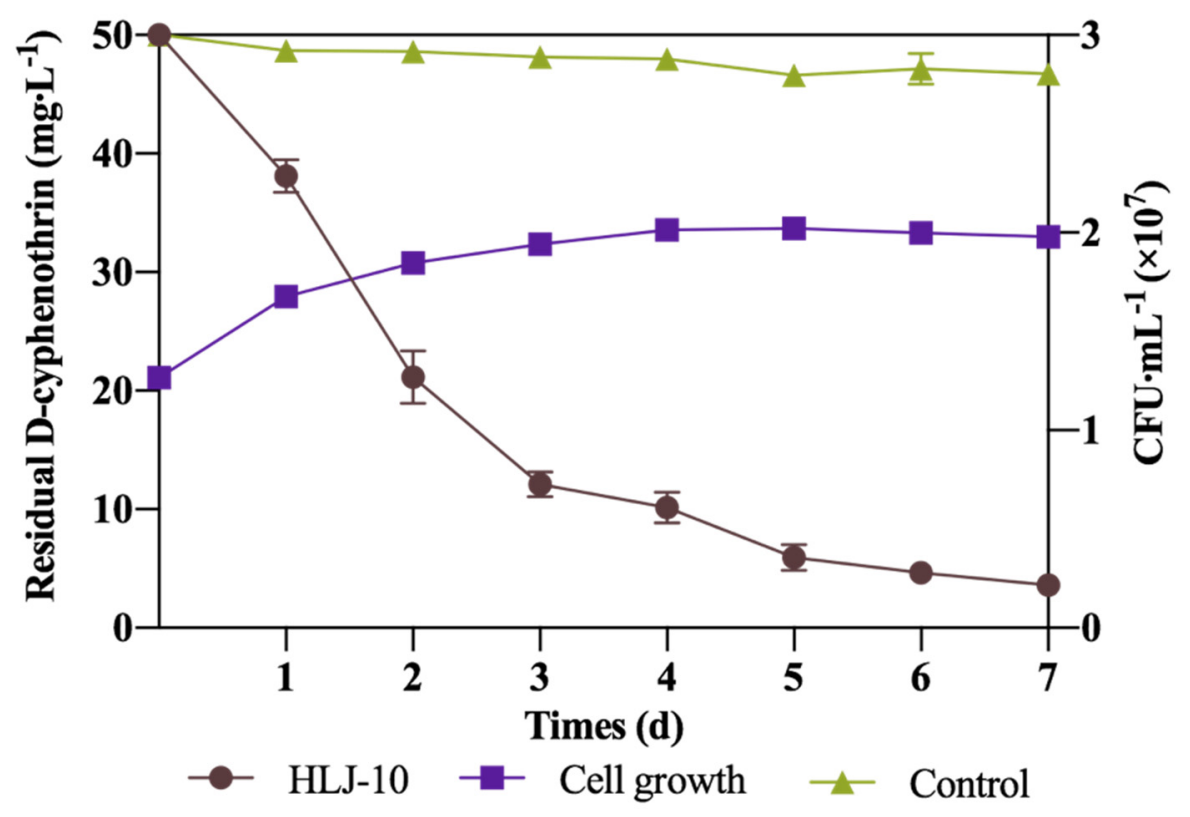

Figure 2. Utilization of D-cyphenothrin during growth of Staphylococcus succinus HLJ-10. Error bars indicate standard deviation of three replicates.

Kinetic parameters of D-cyphenothrin degradation by strain HLJ-10 are shown in Table 2, which reveal that the degradation process of D-cyphenothrin followed a first-order kinetic model (Equation (2)). Degradation constant ( $k$ ) of strain HLJ-10 and control were noted as 0.3896 and 0.011, respectively. Theoretical $t_{1 / 2}$ value of the treatments with strain HLJ-10 and controls were calculated by Equation (3). Determination coefficients $\left(R^{2}\right)$ of strain HLJ-10 and control were found as 0.9659 and 0.983 , respectively, indicating that degradation data were well fitted with first-order kinetic model. The $t_{1 / 2}$ of the D-cyphenothrin degradation by strain HLJ-10 was determined as $1.8 \mathrm{~d}$, which is significantly shorter than $63.0 \mathrm{~d}$ of control. These results further illustrated efficiency of strain HLJ-10 in D-cyphenothrin degradation.

Table 2. Kinetic parameters of D-cyphenothrin degradation with Staphylococcus succinus HLJ-10 in mineral salt medium (MSM).

\begin{tabular}{ccccc}
\hline Treatments & Regression Equation & $\boldsymbol{k}$ & $\boldsymbol{R}^{\mathbf{2}}$ & $\boldsymbol{t}_{\mathbf{1 / 2}}$ \\
\hline Control & $C_{t}=49.8 e^{-0.011 t}$ & 0.011 & 0.9830 & 63.0 \\
HLJ-10 & $C_{t}=50.2 e^{-0.3896 t}$ & 0.3896 & 0.9659 & 1.8 \\
\hline
\end{tabular}

Note: $k$ refers to degradation constant $\left(\right.$ day $\left.^{-1}\right) ; t_{1 / 2}$ refers to half-time (days); $R^{2}$ refers to determination coefficient.

To date, there are only few reports about microbial degradation of D-cyphenothrin. Suzuki et al. recently reported the metabolic behavior of D-cyphenothrin in aqueous environments but D-cyphenothrin-degrading microorganisms were not specified [31]. It is noteworthy that most of pyrethroid-degrading microbes isolated could not grow in the absence of extra carbon sources [42]. Strain HLJ-10 directly utilized D-cyphenothrin as the sole carbon and energy source for its growth that exhibited its promising potential for the bioremediation of pyrethroid-contaminated environments.

\subsection{Optimization of D-Cyphenothrin Degradation Conditions}

Experimental design variables corresponding to D-cyphenothrin degradation are presented in Table 3. Data were analyzed by response surface regression in Design Expert 12.0. Experimental values of D-cyphenothrin residues were fitted to the following quadratic polynomial model equations (Equation (4): 


$$
Y_{1}=94.46-1.6 X_{1}-2.1 X_{2}-0.85 X_{3}+0.2 X_{1} X_{2}+4.1 X_{1} X_{3}-1.15 X_{2} X_{3}-7.56 X_{1}^{2}-10.46 X_{2}^{2}-1.15 X_{3}^{2}
$$

where $Y_{1}$ is the predicted D-cyphenothrin degradation (\%); $X_{1}, X_{2}$, and $X_{3}$ are coded values of temperature, $\mathrm{pH}$, and inoculum size, respectively.

Table 3. Box-Behnken experimental design matrix and response of dependent variable for D-cyphenothrin degradation.

\begin{tabular}{ccccc}
\hline Run & $\boldsymbol{X}_{\mathbf{1}}$ & $\boldsymbol{X}_{\mathbf{2}}$ & $\boldsymbol{X}_{\mathbf{3}}$ & $\boldsymbol{Y}_{\mathbf{1}}$ \\
\hline 1 & 0 & 0 & 0 & 92.8 \\
2 & 0 & 0 & 0 & 94.9 \\
3 & 1 & 1 & 0 & 74.1 \\
4 & 0 & 0 & 0 & 94.9 \\
5 & 1 & 0 & 1 & 91.6 \\
6 & 1 & 0 & -1 & 77.4 \\
7 & -1 & 0 & 1 & 85.9 \\
8 & 0 & -1 & 1 & 82.9 \\
9 & 0 & 0 & 0 & 96.9 \\
10 & -1 & 0 & -1 & 88.1 \\
11 & 0 & 1 & 1 & 73.4 \\
12 & 0 & 1 & -1 & 85.1 \\
13 & -1 & -1 & 0 & 79.2 \\
14 & 1 & -1 & 0 & 74.9 \\
15 & 0 & -1 & -1 & 90.0 \\
16 & -1 & 1 & 0 & 77.6 \\
17 & 0 & 0 & 0 & 92.8 \\
\hline
\end{tabular}

Note: $X_{1}=$ Temperature; $X_{2}=\mathrm{pH} ; X_{3}=$ Inoculum size; $Y_{1}=$ Degradation (\%).

Table 4 presents analysis of variance (ANOVA) to fit a quadratic polynomial model. Significant $p$ value (0.0277) of the model term indicates that the equation reliably predicted D-cyphenothrin degradation. A low coefficient of variation $(\mathrm{CV}=5.41 \%)$ also suggested that the model is accurate and reliable. Results of regression analysis revealed that linear and square terms of temperature $\left(X_{1}\right)$ and $\mathrm{pH}\left(X_{2}\right)$ had significant $(p<0.05)$ effect on D-cyphenothrin degradation by strain HLJ-10, whereas the linear term of inoculum size $\left(X_{3}\right)$ and interaction terms were insignificant $(p>0.05)$. These results were similar to the previous report of Chen et al. [37], who degraded cypermethrin by a co-culture of Bacillus cereus ZH-3 and Streptomyces aureus HP-S-01.

The inoculum size was fixed at OD $0.8\left(6.98 \times 10^{8} \mathrm{CFU} / \mathrm{mL}\right)$ and a three-dimensional response surface was drawn to visually present the effect of temperature and $\mathrm{pH}$ on D-cyphenothrin degradation by strain HLJ-10. As shown in Figure 3, the plot of D-cyphenothrin degradation had a maximum theoretical value of $90.7 \%$ at a stationary point, whereas optimal levels of three variables $X_{1}, X_{2}$, and $X_{3}$ were noted as $2.3,1.9$, and -0.06 at coded levels. The optimum temperature, $\mathrm{pH}$, and inoculum size at the unencoded levels were found as $31.6{ }^{\circ} \mathrm{C}, 7.9$, and $6.05 \times 10^{8} \mathrm{CFU} \cdot \mathrm{mL}^{-1}$, respectively. Strain HLJ-10 was capable of rapidly degrading D-cyphenothrin without a lag phase over a wide range of temperature $\left(25-35{ }^{\circ} \mathrm{C}\right)$ and $\mathrm{pH}(5-9)$. This is a very important feature of an organism for bioremediation of variable environments [30]. Results demonstrated that degradation tends to occur under alkaline conditions which is consistent with SPs characteristic of easy hydrolyzation under alkaline conditions [43]. On the other side, acidity attenuated the activity of S. succinus HLJ-10, which resulted in decreased D-cyphenothrin degradation. 
Table 4. Analysis of variance (ANOVA) of fitted quadratic polynomial model for D-cyphenothrin degradation.

\begin{tabular}{llllll}
\hline Source & DF & SS & MS & F-Value & $p$-Value \\
\hline Model & 9 & 891.53 & 99.06 & 4.64 & 0.0277 \\
$X_{1}$ & 1 & 20.48 & 20.48 & 0.9595 & 0.3599 \\
$X_{2}$ & 1 & 35.28 & 35.28 & 1.65 & 0.2395 \\
$X_{3}$ & 1 & 5.78 & 5.78 & 0.2708 & 0.6188 \\
$X_{1} X_{2}$ & 1 & 0.1600 & 0.1600 & 0.0075 & 0.9334 \\
$X_{1} X_{3}$ & 1 & 67.24 & 67.24 & 3.15 & 0.1192 \\
$X_{2} X_{3}$ & 1 & 5.29 & 5.29 & 0.2478 & 0.6339 \\
$X_{1} X_{1}$ & 1 & 240.33 & 240.33 & 11.26 & 0.0122 \\
$X_{2} X_{2}$ & 1 & 460.24 & 460.24 & 21.56 & 0.0024 \\
$X_{3} X_{3}$ & 1 & 5.62 & 5.62 & 0.2632 & 0.6237 \\
Residual & 7 & 149.41 & 21.34 & & \\
Lack of Fit & 3 & 137.56 & 45.85 & 15.48 & 0.0115 \\
Pure Error & 4 & 11.85 & 2.96 & & \\
Cor Total & 16 & 1040.94 & & & \\
\hline
\end{tabular}

Note: $X_{1}=$ Temperature; $X_{2}=\mathrm{pH} ; X_{3}=$ Inoculum size. DF refers to degrees of freedom; SS refers to sum of sequences; MS refers to mean square. ${ }^{*} p$ level $<0.05$ indicates that model terms are significant.

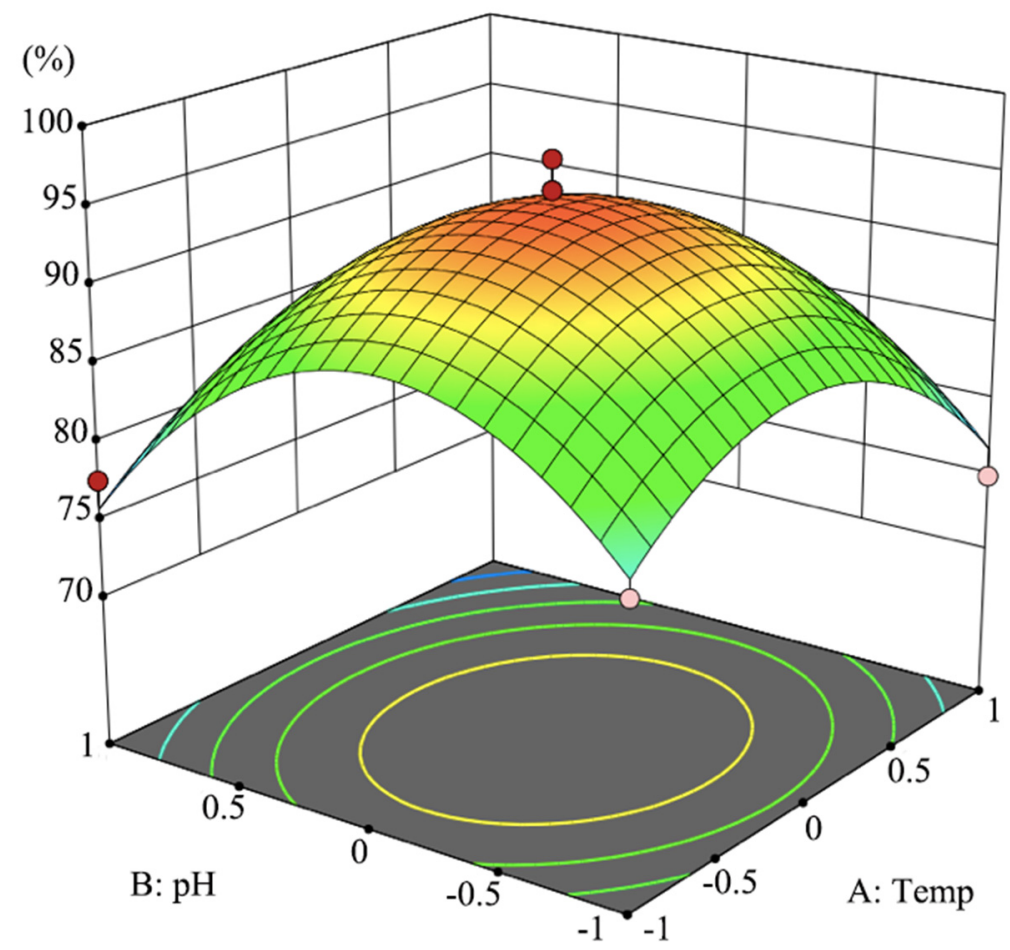

Figure 3. Response surface plot showing the effects of $\mathrm{pH}$ and temperature $\left({ }^{\circ} \mathrm{C}\right)$ on $\mathrm{D}$-cyphenothrin degradation by Staphylococcus succinus HLJ-10 while fixing the zero of inoculum size at a coded level.

\subsection{Degradation Products and Degradation Pathway of D-Cyphenothrin}

The degradation pathway of D-cyphenothrin by strain HLJ-10 was performed through GC/MS. Two significant peaks were detected at retention times of 27.975 and $28.050 \mathrm{~min}$, showing a characteristic mass fragment $\left[\mathrm{M}^{+}\right]$at $m / z 375$ with same major fragment ions at $m / z 123$ and were confirmed as two isomers of the same compound. The compound was designated as compound A having isomers 1 and 2. These two isomers of compound A were further characterized as cis-D-cyphenothrin and trans-D-cyphenothrin according to the fragment retention time (RT) and the similarity of molecular ions to corresponding authentic compounds in the National Institute of Standards and Technology (NIST, 
USA) library database. As the concentration of D-cyphenothrin was decreased, six new compounds B, C, D, E, F, and G were detected. Chemical structures, RTs, and characteristic ions of the mass spectra $(\mathrm{m} / \mathrm{z})$ are listed in Table 5. RTs of compounds B, C, D, E, F, and G were noted as 23.16, 23.14, 23.39, 16.81, 16.76 , and $26.63 \mathrm{~min}$, respectively. Based on the similarity of fragment RTs and molecular ions to those of corresponding authentic compounds in the NIST library database, compounds B, C, D, E, F, and G were identified as trans-2,2-dimethyl-3-propenyl-cyclopropanol, 2,2-dimethyl-3-propenyl-cyclopropionic acid, trans-2,2-dimethyl-3-propenyl-cyclopropionaldehyde, $\alpha$-hydroxy-3-phenoxy-benzeneacetonitrile, 3-phenoxybenzaldehyde, and 1,2-benzenedicarboxylic acid and dipropyl ester, respectively (Figure S3). Mass spectrum of the matched D-cyphenothrin metabolites in the NIST library database are shown in Figure S4.

Table 5. Chromatographic properties of D-cyphenothrin metabolites during degradation with Staphylococcus succinus HLJ-10.

\begin{tabular}{|c|c|c|c|c|}
\hline Code & RT (min) & $m / z$ & Compound Structure & Name \\
\hline $\mathrm{A}_{1}$ & 27.975 & 375 & & (cis) D-cyphenothrin \\
\hline $\mathrm{A}_{2}$ & 28.050 & 375 & & (trans) D-cyphenothrin \\
\hline B & 23.160 & 156 & & trans-2,2-Dimethyl-3-propenyl-cyclopropanol \\
\hline C & 23.144 & 172 & & 2,2-Dimethyl-3-propenyl-cyclopropionic acid \\
\hline $\mathrm{D}$ & 23.399 & 154 & & trans-2,2-Dimethyl-3-propenyl-cyclopropionaldehyde \\
\hline $\mathrm{E}$ & 16.814 & 227 & & $\alpha$-Hydroxy-3-phenoxy-benzeneacetonitrile \\
\hline $\mathrm{F}$ & 16.765 & 198 & & 3-Phenoxybenzaldehyde \\
\hline G & 26.634 & 232 & & 1,2-Benzenedicarboxylic acid, dipropyl ester \\
\hline
\end{tabular}

Based on the GC/MS results, the microbial degradation pathway of D-cyphenothrin was first time proposed (Figure 4). D-cyphenothrin was first hydrolyzed by the cleavage of carboxylester linkage to yield $\alpha$-hydroxy-3-phenoxy-benzeneacetonitrile and trans-2,2-dimethyl-3-propenyl-cyclopropanol. Intermediate product $\alpha$-hydroxy-3-phenoxy-benzeneacetonitrile was unstable in the environment and spontaneously converted to 3-phenoxybenzaldehyde. Subsequently, 3-phenoxybenzaldehyde was further degraded through diaryl cleavage to form 1,2-benzenedicarboxylic acid and dipropyl ester. Meanwhile, trans-2,2-dimethyl-3-propenyl-cyclopropanol was oxidized to form trans-2,2-dimethyl-3-propenyl-cyclopropionaldehyde, which was transient and further oxidized to 2,2-dimethyl-3-propenyl-cyclopropionic acid. At the end of experiment, all these metabolites faded away without any non-cleavable metabolites. In the non-inoculated controls with the same quantity of D-cyphenothrin, only D-cyphenothrin was detected after $7 \mathrm{~d}$. 


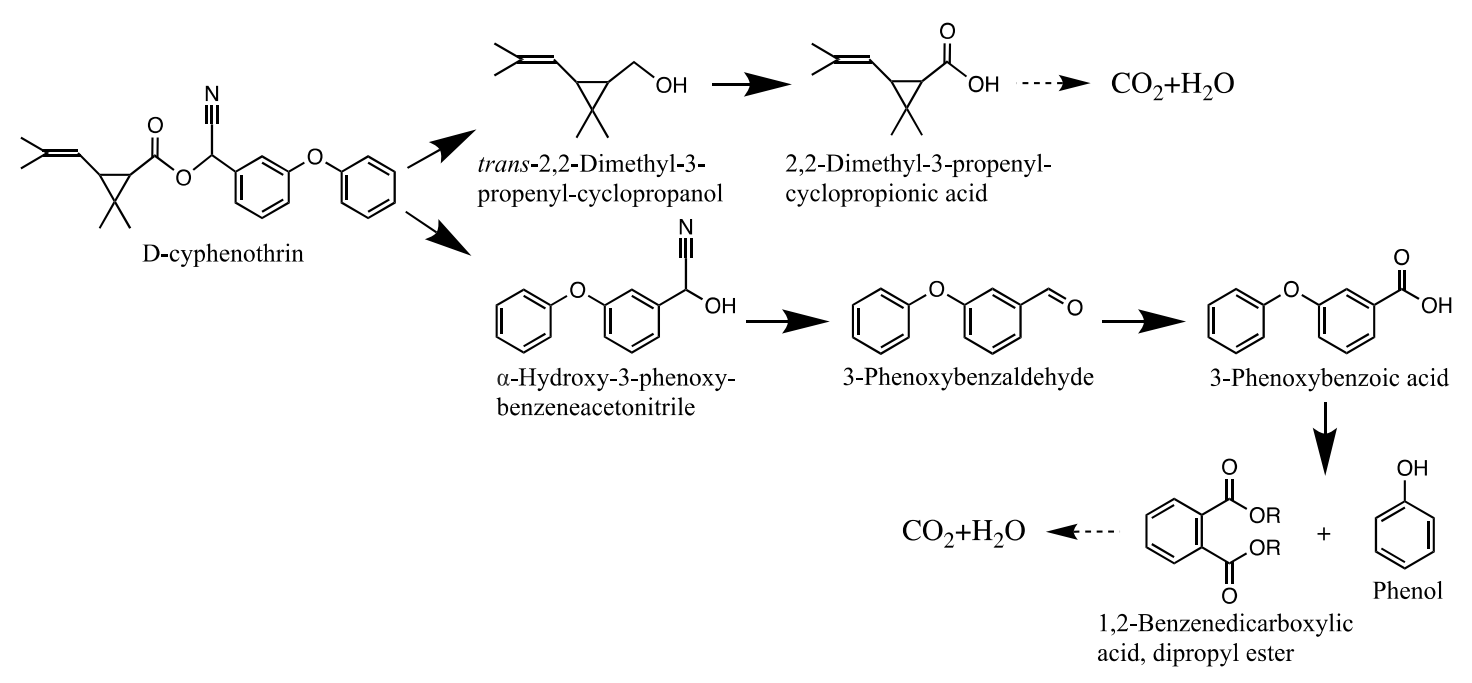

Figure 4. Proposed D-cyphenothrin degradation pathway in Staphylococcus succinus HLJ-10.

Among these compounds, $\alpha$-hydroxy-3-phenoxy-benzeneacetonitrile and 3-phenoxybenzaldehyde have been frequently detected in SPs biodegradation [18,35]. These intermediates were transient with very low concentrations and easily transformed into smaller molecular compounds through oxidation and hydrolysis. Microbial degradation of pyrethroids mainly involves the hydrolysis of ester bonds and oxidation reaction [23]. Carboxylesterase enzyme is produced by the microorganism that specifically cleaves a carboxylate bond $[44,45]$. This cleavage transforms parent pesticide into the smaller molecular weight compound containing a carboxylic acid or alcohol that further oxidizes and dehydrogenates to yield less toxic or non-toxic compounds [46,47]. It is worth noting that the D-cyphenothrin degradation products are non-toxic to the environment.

\subsection{Degradation of Various SPs and Different Concentrations of D-Cyphenothrin}

In order to study the degradation potential of strain HLJ-10 under different environments, degradation experiments were carried out with different concentrations of D-cyphenothrin (Figure 5A) and $50 \mathrm{mg} \cdot \mathrm{L}^{-1}$ of various SPs (Figure $5 \mathrm{~B}$ ). Initial concentrations of D-cyphenothrin were prepared as $25,50,100,200,400$, and $800 \mathrm{mg} \cdot \mathrm{L}^{-1}$, respectively. The highest degradation $(92.8 \%)$ was noted at $50 \mathrm{mg} \cdot \mathrm{L}^{-1}$. Unexpectedly, at $25 \mathrm{mg} \cdot \mathrm{L}^{-1}$, D-cyphenothrin was not completely degraded and maximum degradation reached $91.8 \%$. Strain HLJ-10 rapidly degraded D-cyphenothrin at concentrations up to $800 \mathrm{mg} \cdot \mathrm{L}^{-1}$ and utilized it as a sole carbon and energy source to grow without any lag period. At a D-cyphenothrin concentration of $800 \mathrm{mg} \cdot \mathrm{L}^{-1}$, maximum degradation reached $74.6 \%$ after $7 \mathrm{~d}$. Previous studies revealed that the degradation activity of pyrethroid-degrading bacterial strains was substantially inhibited at high SPs concentrations $[48,49]$. This particular strain was found highly effective in degrading D-cyphenothrin up to the concentration as high as $800 \mathrm{mg} \cdot \mathrm{L}^{-1}$, indicating that strain HLJ-10 may be suitable for the bioremediation of various contaminated environments. 


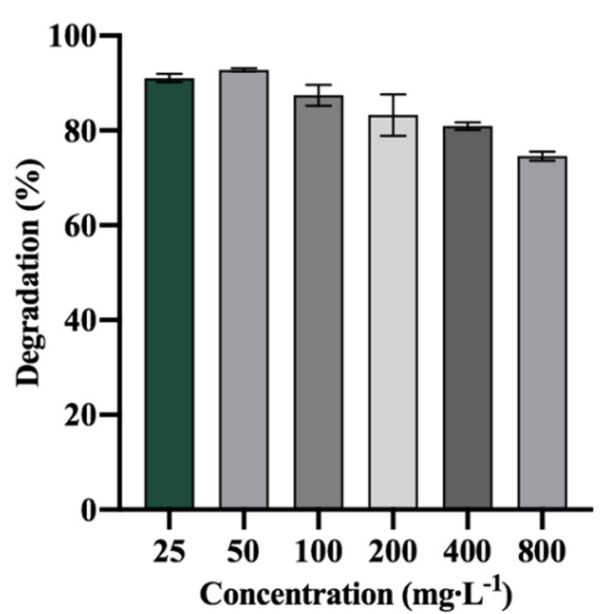

A

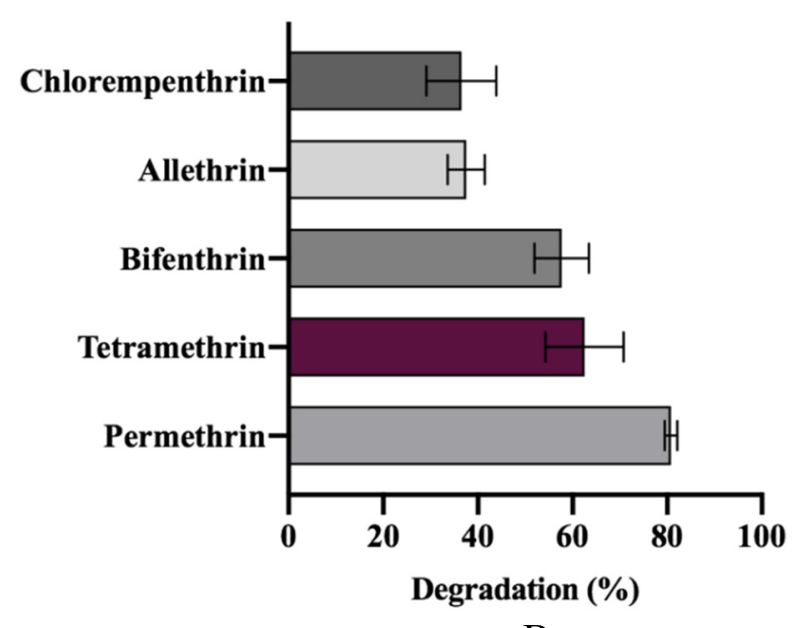

$\mathrm{B}$

Figure 5. (A) Degradation of different initial concentrations of D-cyphenothrin by Staphylococcus succinus HLJ-10; (B) Degradation of various pyrethroids by Staphylococcus succinus HLJ-10.

Generally, multiple SPs are used in rotation instead of repeating a single pyrethroid for a longer time. Therefore, residues of various SPs are found in terrestrial and aquatic environments $[50,51]$. Different SPs including tetramethrin, permethrin, bifenthrin, allethrin, and chlorempenthrin were separately added to the MSM medium at a final concentration of $50 \mathrm{mg} \cdot \mathrm{L}^{-1}$. Degradation of permethrin was found to be the highest $(80.8 \%)$, followed by tetramethrin $(62.5 \%)$. The lowest degradation occurred in allethrin and chlorempenthrin as $37.5 \%$ and $36.5 \%$, respectively. Usually, the degraders only transform a single xenobiotic compound due to certain structural requirements [40]. Strain HLJ-10 was able to degrade a wide range of SPs, suggesting that the isolate possesses promising potential and advantages in removing pyrethroid residues from various environments.

\subsection{Biodegradation of D-Cyphenothrin in Soils}

Soil remediation experiments were carried out under sterile and nonsterile conditions, whereas non-inoculated treatment served as the control (Figure 6). After bioremediation with strain HLJ-10, approximately $77.2 \%$ and $72.8 \%$ of the initially added D-cyphenothrin was eliminated in nonsterile and sterile soils, respectively, within $40 \mathrm{~d}$. Degradation parameters were characterized as $k$ values of 0.0323 and 0.0283 day $^{-1}$ and $t_{1 / 2}$ values of 21.5 and $24.5 \mathrm{~d}$, respectively. Specific kinetic parameters are shown in Table 6. In addition, no significant lag phase was observed during the experiment. In the controls with indigenous microbiota, $52.5 \%$ of D-cyphenothrin was removed, which is slightly higher than sterilized control (48.2\%) and $t_{1 / 2}$ values were noted as 46.2 and $55.5 \mathrm{~d}$, respectively, indicating that indigenous microbiota play a role in the bioaugmentation of pyrethroid-contaminated sites. Similar results were observed by Zhan et al. [35]. Nonsterile soil contains natural microbial communities, which led to a higher degradation rate. 


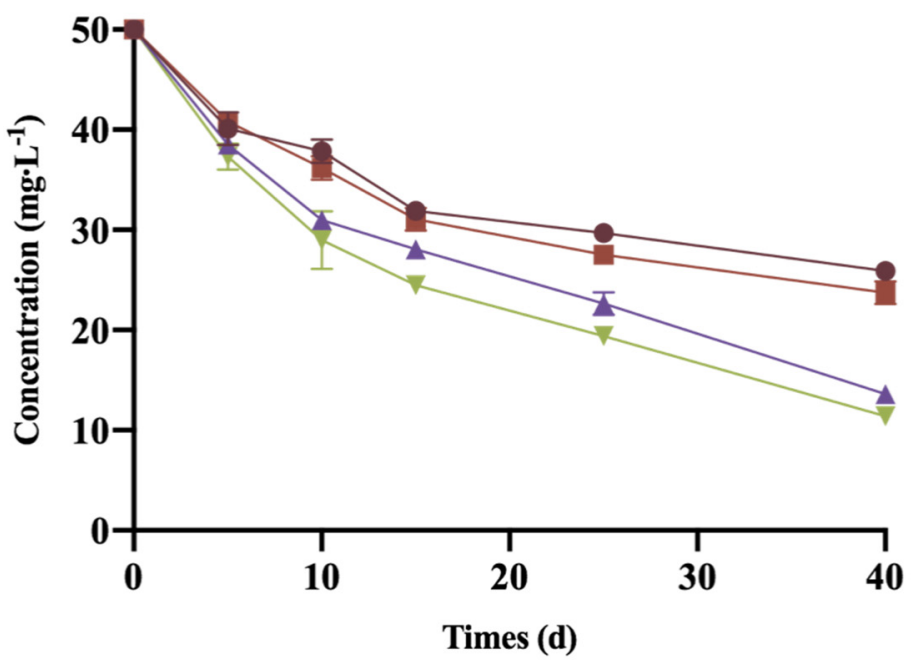

\footnotetext{
- - Sterile soils + D-cyphenothrin

- Sterile soils + D-cyphenothrin + HLJ-10
}
- - Nonsterile soils + D-cyphenothrin
$\rightarrow-$ Nonsterile soils + D-cyphenothrin + HLJ-10

Figure 6. Degradation kinetics of D-cyphenothrin in different soils.

Table 6. Kinetic parameters of D-cyphenothrin degradation with Staphylococcus succinus HLJ-10 in sterile and nonsterile soils.

\begin{tabular}{ccccc}
\hline Treatments & $\begin{array}{c}\text { Regression } \\
\text { Equation }\end{array}$ & $\boldsymbol{k}$ & $\boldsymbol{R}^{\mathbf{2}}$ & $\boldsymbol{t}_{\mathbf{1 / 2}}$ \\
\hline Sterile soils + D-cyphenothrin & $C_{t}=50.3 e^{-0.011 t}$ & 0.0124 & 0.9302 & 55.9 \\
Nonsterile soils + D-cyphenothrin & $C_{t}=51.8 e^{-0.3896 t}$ & 0.015 & 0.942 & 46.2 \\
Sterile soils + D-cyphenothrin + HLJ-10 & $C_{t}=51.2 e^{-0.3896 t}$ & 0.0283 & 0.9878 & 24.5 \\
Nonsterile soils + D-cyphenothrin + HLJ-10 & $C_{t}=52.1 e^{-0.3896 t}$ & 0.0323 & 0.9899 & 21.5 \\
\hline
\end{tabular}

$k$ refers to degradation constant $\left(\right.$ day $\left.^{-1}\right) ; t_{1 / 2}$ refers to half-time (days); $R^{2}$ refers to determination coefficient. Note: like other footnote.

Several pyrethroid-degrading microbes were reported and effectively removed pyrethroids under optimum conditions in liquid media, but few were subjected to soil remediation [33,40,42,52,53]. The degrading microbes isolated from the environment usually fail to degrade xenobiotics when used for bioremediation of contaminated soils; thus, additional treatments are needed to accelerate biodegradation $[23,43,54]$. In this work, bioaugmentation of D-cyphenothrin-contaminated soils with strain HLJ-10 substantially enhanced the disappearance rate of D-cyphenothrin, and its $t_{1 / 2}$ was reduced by 31.0 and $24.7 \mathrm{~d}$ in sterile and nonsterile soils, respectively, in comparison with soils without the strain HLJ-10. Unlike most bacterial isolates, strain HLJ-10 has an exceptional ability to adapt and thrive in different ecological niches, which makes it a potent strain for various applications.

However, it is worth noting that the strain HLJ-10 exhibited a significant reduction in the ability to remediate soil compared with the liquid medium experiment. Microorganisms in the soil are more likely to be affected by factors such as $\mathrm{pH}$, soil water content, organic matter content, soil porosity, heavy metals, and other organic contaminants than by liquid media [46,55-57]. To improve the ability of strain HLJ-10 to remediate in soil, these issues should be fully considered.

\section{Conclusions}

In this study, we identified a novel bacterial isolate S. succinus HLJ-10 having superb D-cyphenothrin degradation activity. Strain HLJ-10 utilized D-cyphenothrin as the sole carbon source for its growth over a wide range of temperature $\left(25-35^{\circ} \mathrm{C}\right)$ and $\mathrm{pH}(5-9)$, indicating that the strain has excellent working ability in adverse environments. This study proves that the bacterium 
harbors the metabolic pathway for complete detoxification and metabolism of D-cyphenothrin. This is the first report of the D-cyphenothrin degradation pathway that is of vital importance in the D-cyphenothrin biogeocycle. Further, this particular strain exhibited great advantages in bioremediation of D-cyphenothrin-contaminated soils because of its adaptability in different environments. Furthermore, this strain was capable of degrading a wide range of SPs, suggesting that strain HLJ-10 is a potent and effective candidate for the bioremediation of pyrethroid-contaminated terrestrial and aquatic environments. However, further studies, such as its interaction with environment, degradation enzymes, and genes that encode for key enzymes, are still needed before the application of this strain in the field-scale bioremediation.

Supplementary Materials: The following are available online at http://www.mdpi.com/2076-2607/8/4/473/s1. Figure S1: External morphology and scanning electron micrograph of strain HLJ-10. Pictures a (6420x) and b $(21880 \times)$ are scanning electron micrographs. Picturesc and $d$ are front and back sides of strain HLJ-10 grown on LB agar plates. Figure S2: HPLC analysis of D-cyphenothrin degradation by strain HLJ-10 over time. Figure S3: Mass spectrum of GC-MS identified for D-cyphenothrin intermediates. A1 and A2 were isomers of D-cyphenothrin, and B to G were trans-2,2-dimethyl-3-propenyl-cyclopropanol, 2,2-dimethyl-3-propenyl-cyclopropionic acid, trans-2,2dimethyl-3-propenyl-cyclopropionaldehyde, $\alpha$-hydroxy-3-phenoxy-benzeneacetonitrile, 3-phenoxybenzaldehyde, and 1,2-benzenedicarboxylic acid, dipropyl ester, respectively. Figure S4: The mass spectra of D-cyphenothrin metabolites reported in the National Institute of Standards and Technology (NIST, USA) library database. (a) trans-2,2-dimethyl-3-propenyl-cyclopropanol; (b) 2,2-dimethyl-3-propenyl-cyclopropionic acid; (c) trans-2,2-dimethyl-3-propenyl-cyclopropionaldehyde; (d) $\alpha$-hydroxy-3-phenoxy-benzeneacetonitrile; (e) 3-phenoxybenzaldehyde; (f) 1,2-benzenedicarboxylic acid, dipropyl ester. Table S1: Physiological and biochemical characteristics of strain HLJ-10.

Author Contributions: Conceptualization: S.C.; methodology: Y.H. and S.C.; data analysis: Y.H., Z.L., and W.Z.; writing—original draft preparation: Y.H.; writing—review and editing: Z.L., W.Z., S.P., P.B., E.R.R., A.J.K., and S.C.; supervision, funding acquisition, and project administration: S.C. All authors have read and agreed to the published version of the manuscript.

Funding: This study was funded by the Key-Area Research and Development Program of Guangdong Province (2018B020206001), National Natural Science Foundation of China (31401763) and Guangdong Special Branch Plan for Young Talent with Scientific and Technological Innovation (2017TQ04N026).

Conflicts of Interest: The authors declare no conflict of interest. The funders had no role in the design of the study; in the collection, analyses, or interpretation of data; in the writing of the manuscript, or in the decision to publish the results.

\section{References}

1. WHO. WHO Specifications and Evaluations for Public Health Pesticides, d,d,trans-Cyphenothrin. WHO 2005. Available online: https://www.who.int/whopes/en/ (accessed on 20 March 2020).

2. Beltran, J.; Peruga, A.; Pitarch, E.; Lopez, F.J.; Hernandez, F. Application of solid-phase microextraction for the determination of pyrethroid residues in vegetable samples by GC-MS. Anal. Bioanal. Chem. 2003, 376, 502-511. [CrossRef] [PubMed]

3. Mendis, J.C.; Tennakoon, T.K.; Jayasinghe, C.D. Zebrafish embryo toxicity of a binary mixture of pyrethroid insecticides: D-tetramethrin and cyphenothrin. J. Toxicol. 2018, 2018, 1-8. [CrossRef] [PubMed]

4. Stara, J.; Stejskal, V.; Nesvorna, M.; Plachy, J.; Hubert, J. Efficacy of selected pesticides against synanthropic mites under laboratory assay. Pest. Manag. Sci. 2011, 67, 446-457. [CrossRef]

5. Tilak, R.; Agrawal, V.K.; Dutta, J. Field performance of cyphenothrin: An integrated insecticide strategy against German cockroaches (Dictyoptera: Blatellidae). J. Vector. Borne. Dis. 2005, 42, 68-73.

6. Zhan, H.; Huang, Y.; Lin, Z.; Bhatt, P.; Chen, S. New insights into the microbial degradation and catalytic mechanism of synthetic pyrethroids. Environ. Res. 2020, 182, 109138. [CrossRef]

7. Cycon, M.; Piotrowska-Seget, Z. Pyrethroid-degrading microorganisms and their potential for the bioremediation of contaminated soils: A review. Front. Microbiol. 2016, 7, 1463. [CrossRef]

8. Kodaka, R.; Sugano, T.; Katagi, T. Degradation of esfenvalerate in illuminated water-sediment system. J. Pestic. Sci. 2009, 34, 27-36. [CrossRef]

9. Kasai, S. Role of cytochrome P450 in mechanism of pyrethroid resistance. J. Pestic. Sci. 2004, 29, $220-221$. [CrossRef] 
10. Sakata, S.; Mikami, N.; Yamada, H. Degradation of pyrethroid optical isomers in soils. J. Pestic. Sci. 1992, 17, 169-180. [CrossRef]

11. Pham, M.H.; Sebesvari, Z.; Tu, B.M.; Pham, H.V.; Renaud, F.G. Pesticide pollution in agricultural areas of Northern Vietnam: Case study in Hoang Liet and Minh Dai communes. Environ. Pollut. 2011, 159, 3344-3350. [PubMed]

12. Hadnagy, W.; Leng, G.; Sugiri, D.; Ranft, U.; Idel, H. Pyrethroids used indoors - Immune status of humans exposed to pyrethroids following a pest control operation - a one year follow-up study. Int. J. Hyg. Envir. Heal. 2003, 206, 93-102. [CrossRef] [PubMed]

13. Muller-Mohnssen, H. Chronic sequelae and irreversible injuries following acute pyrethroid intoxication. Toxicol. Lett. 1999, 107, 161-176. [CrossRef]

14. Stiller-Winkler, R.; Hadnagy, W.; Leng, G.; Straube, E.; Idel, H. Immunological parameters in humans exposed to pesticides in the agricultural environment. Toxicol. Lett. 1999, 107, 219-224. [CrossRef]

15. Yousef, M.I. Vitamin E modulates reproductive toxicity of pyrethroid lambda-cyhalothrin in male rabbits. Food Chem. Toxicol. 2010, 48, 1152-1159. [CrossRef]

16. Le Grand, R.; Dulaurent, S.; Gaulier, J.M.; Saint-Marcoux, F.; Moesch, C.; Lachatre, G. Simultaneous determination of five synthetic pyrethroid metabolites in urine by liquid chromatography-tandem mass spectrometry: Application to 39 persons without known exposure to pyrethroids. Toxicol. Lett. 2012, 210, 248-253. [CrossRef]

17. Leng, G.; Ranft, U.; Sugiri, D.; Hadnagy, W.; Berger-Preiss, E.; Idel, H. Pyrethroids used indoors - Biological monitoring of exposure to pyrethroids following an indoor pest control operation. Int. J. Hyg. Envir. Heal. 2003, 206, 85-92. [CrossRef]

18. Chen, S.; Chang, C.Q.; Deng, Y.Y.; An, S.W.; Dong, Y.H.; Zhou, J.N.; Hu, M.Y.; Zhong, G.H.; Zhang, L.H. Fenpropathrin biodegradation pathway in Bacillus sp. DG-02 and its potential for bioremediation of pyrethroid-contaminated soils. J. Agric. Food Chem. 2014, 62, 2147-2157. [CrossRef]

19. Chen, S.; Hu, M.Y.; Liu, J.J.; Zhong, G.H.; Yang, L.; Rizwan-ul-Haq, M.; Han, H.T. Biodegradation of beta-cypermethrin and 3-phenoxybenzoic acid by a novel Ochrobactrum lupini DG-S-01. J. Hazard. Mater. 2011, 187, 433-440. [CrossRef]

20. Zhan, H.; Feng, Y.; Fan, X.; Chen, S. Recent advances in glyphosate biodegradation. Appl. Microbiol. Biotechnol. 2018, 10, 5033-5043. [CrossRef]

21. Chen, S.; Geng, P.; Xiao, Y.; Hu, M.Y. Bioremediation of beta-cypermethrin and 3-phenoxybenzaldehyde contaminated soils using Streptomyces aureus HP-S-01. Appl. Microbiol. Biotechnol. 2012, 94, 505-515. [CrossRef] [PubMed]

22. Xiao, Y.; Chen, S.H.; Gao, Y.Q.; Hu, W.; Hu, M.Y.; Zhong, G.H. Isolation of a novel beta-cypermethrin degrading strain Bacillus subtilis BSF01 and its biodegradation pathway. Appl. Microbiol. Biotechnol. 2015, 99, 2849-2859. [CrossRef] [PubMed]

23. Yang, J.; Feng, Y.; Zhan, H.; Liu, J.; Yang, F.; Zhang, K.; Zhang, L.; Chen, S. Characterization of a pyrethroid-degrading Pseudomonas fulva strain P31 and biochemical degradation pathway of D-phenothrin. Front. Microbiol. 2018, 9, 1003. [CrossRef] [PubMed]

24. Zhang, S.B.; Zhang, D.Y.; Liu, Y.; Luo, X.W.; Cheng, F.X.; Luo, Y.H.; Cheng, J.E.; Ma, X.M. Degradation characteristics and pathway of fenpropathrin by Rhodopseudomonas sp. strain PSB07-6. Fresen. Environ. Bull. 2009, 18, 2060-2065.

25. Birolli, W.G.; Arai, M.S.; Nitschke, M.; Porto, A.L.M. The pyrethroid ( \pm )-lambda-cyhalothrin enantioselective biodegradation by a bacterial consortium. Pest. Biochem. Physiol. 2019, 156, 129-137. [CrossRef]

26. Cycoń, M.; Żmijowska, A.; Piotrowska-Seget, Z. Enhancement of deltamethrin degradation by soil bioaugmentation with two different strains of Serratia marcescens. Int. J. Environ. Sci. Technol. 2014, 11, 1305-1316. [CrossRef]

27. Bhatt, P.; Huang, Y.; Zhang, W.; Sharma, A.; Chen, S. Enhanced cypermethrin degradation kinetics and metabolic pathway in Bacillus thuringiensis strain SG4. Microorganisms 2020, 8, 223. [CrossRef]

28. Birolli, W.G.; Alvarenga, N.; Seleghim, M.H.; Porto, A.L. Biodegradation of the pyrethroid pesticide esfenvalerate by marine-derived fungi. Mar. Biotechnol. 2016, 18, 511-520. [CrossRef]

29. Birolli, W.G.; Vacondio, B.; Alvarenga, N.; Seleghim, M.H.R.; Porto, A.L.M. Enantioselective biodegradation of the pyrethroid (+/-)-lambda-cyhalothrin by marine-derived fungi. Chemosphere 2018, 197, 651-660. [CrossRef] 
30. Chen, S.; Hu, Q.B.; Hu, M.Y.; Luo, J.J.; Weng, Q.F.; Lai, K.P. Isolation and characterization of a fungus able to degrade pyrethroids and 3-phenoxybenzaldehyde. Bioresour. Technol. 2011, 102, 8110-8116. [CrossRef]

31. Suzuki, Y.; Yoshida, M.; Sugano, T.; Shibata, A.; Kodaka, R.; Fujisawa, T.; Katagi, T. Behavior of cyphenothrin in aquatic environment. J. Pestic. Sci. 2017, 42, 17-24. [CrossRef] [PubMed]

32. Sogorb, M.A.; Vilanova, E. Enzymes involved in the detoxification of organophosphorus, carbamate and pyrethroid insecticides through hydrolysis. Toxicol. Lett. 2002, 128, 215-228. [CrossRef]

33. Zhai, Y.; Li, K.; Song, J.; Shi, Y.; Yan, Y. Molecular cloning, purification and biochemical characterization of a novel pyrethroid-hydrolyzing carboxylesterase gene from Ochrobactrum anthropi YZ-1. J. Hazard. Mater. 2012, 221-222, 206-212. [CrossRef] [PubMed]

34. Deng, W.Q.; Lin, D.R.; Yao, K.; Yuan, H.Y.; Wang, Z.L.; Li, J.L.; Zou, L.K.; Han, X.F.; Zhou, K.; He, L.; et al. Characterization of a novel beta-cypermethrin-degrading Aspergillus niger YAT strain and the biochemical degradation pathway of beta-cypermethrin. Appl. Microbiol. Biotechnol. 2015, 99, 8187-8198. [CrossRef] [PubMed]

35. Zhan, H.; Wang, H.; Liao, L.; Feng, Y.; Fan, X.; Zhang, L.; Chen, S. Kinetics and novel degradation pathway of permethrin in Acinetobacter baumannii ZH-14. Front. Microbiol. 2018, 9, 98. [CrossRef] [PubMed]

36. Tamura, K.; Dudley, J.; Nei, M.; Kumar, S. MEGA4: Molecular evolutionary genetics analysis (MEGA) software version 4.0. Mol. Biol. Evol. 2007, 24, 1596-1599. [CrossRef]

37. Chen, S.; Luo, J.J.; Hu, M.Y.; Lai, K.P.; Geng, P.; Huang, H.S. Enhancement of cypermethrin degradation by a coculture of Bacillus cereus ZH-3 and Streptomyces aureus HP-S-01. Bioresour. Technol. 2012, 110, 97-104. [CrossRef]

38. Zhang, X.Q.; Hao, X.; Huo, S.; Lin, W.; Xia, X.; Liu, K.; Duan, B. Isolation and identification of the Raoultella ornithinolytica-ZK4 degrading pyrethroid pesticides within soil sediment from an abandoned pesticide plant. Arch. Microbiol. 2019, 6, 1-11. [CrossRef]

39. Wu, P.C.; Liu, Y.H.; Wang, Z.Y.; Zhang, X.Y.; Li, H.; Liang, W.Q.; Luo, N.; Hu, J.M.; Lu, J.Q.; Luan, T.G.; et al. Molecular cloning, purification, and biochemical characterization of a novel pyrethroid-hydrolyzing esterase from Klebsiella sp. strain ZD112. J. Agric. Food Chem. 2006, 54, 836-842. [CrossRef]

40. Chen, S.; Dong, Y.H.; Chang, C.Q.; Deng, Y.Y.; Zhang, X.F.; Zhong, G.H.; Song, H.W.; Hu, M.Y.; Zhang, L.H. Characterization of a novel cyfluthrin-degrading bacterial strain Brevibacterium aureum and its biochemical degradation pathway. Bioresour. Technol. 2013, 132, 16-23. [CrossRef]

41. Chen, S.; Yang, L.; Hu, M.; Liu, J. Biodegradation of fenvalerate and 3-phenoxybenzoic acid by a novel Stenotrophomonas sp. strain ZS-S-01 and its use in bioremediation of contaminated soils. Appl. Microbiol. Biotechnol. 2011, 90, 755-767. [CrossRef] [PubMed]

42. Maloney, S.E.; Maule, A.; Smith, A.R. Microbial transformation of the pyrethroid insecticides: Permethrin, deltamethrin, fastac, fenvalerate, and fluvalinate. Appl. Environ. Microb. 1988, 54, 2874-2876. [CrossRef]

43. Liu, J.; Chen, S.; Ding, J.; Xiao, Y.; Han, H.; Zhong, G. Sugarcane bagasse as support for immobilization of Bacillus pumilus HZ-2 and its use in bioremediation of mesotrione-contaminated soils. Appl. Microbiol. Biotechnol. 2015, 99, 10839-10851. [CrossRef] [PubMed]

44. Bhatt, P.; Bhatt, K.; Huang, Y.; Lin, Z.; Chen, S. Esterase is a powerful tool for the biodegradation of pyrethroid insecticides. Chemosphere 2020, 244, 125507. [CrossRef] [PubMed]

45. Wang, B.; Guo, P.; Hang, B.; Li, L.; He, J.; Li, S.P. Cloning of a novel pyrethroid-hydrolyzing carboxylesterase gene from Sphingobium sp. strain JZ-1. Appl. Environ. Microbiol. 2009, 75, 5496-5500. [CrossRef] [PubMed]

46. Huang, Y.; Zhan, H.; Bhatt, P.; Chen, S. Paraquat degradation from contaminated environments: Current achievements and perspectives. Front. Microbiol. 2019, 10, 1754. [CrossRef]

47. Bhatt, P.; Huang, Y.; Zhan, H.; Chen, S. Insight into microbial applications for the biodegradation of pyrethroid insecticides. Front. Microbiol. 2019, 10, 1778. [CrossRef]

48. Tang, A.X.; Wang, B.W.; Liu, Y.Y.; Li, Q.Y.; Tong, Z.F.; Wei, Y.J. Biodegradation and extracellular enzymatic activities of Pseudomonas aeruginosa strain GF31 on beta-cypermethrin. Environ. Sci. Pollut. R. 2015, 22, 13049-13057. [CrossRef]

49. Zhang, H.; Zhang, Y.M.; Hou, Z.G.; Wang, X.M.; Wang, J.; Lu, Z.B.; Zhao, X.F.; Sun, F.J.; Pan, H.Y. Biodegradation potential of deltamethrin by the Bacillus cereus strain $\mathrm{Y} 1$ in both culture and contaminated soil. Int. Biodeter. Biodegr. 2016, 106, 53-59. [CrossRef]

50. Aznar, R.; Moreno-Ramon, H.; Albero, B.; Sanchez-Brunete, C.; Tadeo, J.L. Spatio-temporal distribution of pyrethroids in soil in Mediterranean paddy fields. J. Soil. Sediment. 2017, 17, 1503-1513. [CrossRef] 
51. Major, K.M.; Weston, D.P.; Lydy, M.J.; Wellborn, G.A.; Poynton, H.C. Unintentional exposure to terrestrial pesticides drives widespread and predictable evolution of resistance in freshwater crustaceans. Evol. Appl. 2018, 11, 748-761. [CrossRef] [PubMed]

52. Bhatt, P.; Huang, Y.; Rene, E.R.; Kumar, A.J.; Chen, S. Mechanism of allethrin biodegradation by a newly isolated Sphingomonas trueperi strain CW3 from wastewater sludge. Bioresour. Technol. 2020, 305, 123074. [CrossRef] [PubMed]

53. Chen, S.; Deng, Y.; Chang, C.; Lee, J.; Cheng, Y.; Cui, Z.; Zhou, J.; He, F.; Hu, M.; Zhang, L.H. Pathway and kinetics of cyhalothrin biodegradation by Bacillus thuringiensis strain ZS-19. Sci. Rep. 2015, 5, 8784. [CrossRef] [PubMed]

54. Lin, Z.; Zhang, W.; Pang, S.; Huang, Y.; Mishra, S.; Bhatt, P.; Chen, S. Current approaches to and future perspectives on methomyl degradation in contaminated soil/water environments. Molecules 2020, 25, 738. [CrossRef] [PubMed]

55. Cycoń, M.; Mrozik, A.; Piotrowska-Seget, Z. Bioaugmentation as a strategy for the remediation of pesticide-polluted soil: A review. Chemosphere 2017, 172, 52-71.

56. Feng, Y.; Huang, Y.; Zhan, H.; Bhatt, P.; Chen, S. An overview of strobilurin fungicide degradation: Current status and future perspective. Front. Microbiol. 2020, 11, 389. [CrossRef]

57. Zhang, W.; Lin, Z.; Pang, S.; Bhatt, P.; Chen, S. Insights into the biodegradation of lindane ( $\gamma$-hexachlorocyclohexane) using a microbial system. Front. Microbiol. 2020, 11, 522.

(C) 2020 by the authors. Licensee MDPI, Basel, Switzerland. This article is an open access article distributed under the terms and conditions of the Creative Commons Attribution (CC BY) license (http://creativecommons.org/licenses/by/4.0/). 